\title{
MHC class I diversity predicts non-random mating in Chinese alligators (Alligator sinensis)
}

\author{
Qun-Hua Han ${ }^{1} \cdot$ Ru-Na Sun ${ }^{1} \cdot$ Hai-Qiong Yang ${ }^{1} \cdot$ Zhen-Wei Wang $^{2}$ - Qiu-Hong Wan ${ }^{1} \cdot$ Sheng-Guo Fang ${ }^{1}$
}

Received: 31 August 2018 / Revised: 26 November 2018 / Accepted: 28 November 2018 / Published online: 22 January 2019

(c) The Author(s) 2019. This article is published with open access

\begin{abstract}
The major histocompatibility complex (MHC) has several important roles in kin recognition, pathogen resistance and mate selection. Research in fish, birds and mammals has suggested that individuals optimise MHC diversity, and therefore offspring fitness, when choosing mates. In reptiles, however, it is unclear whether female mate choice is based on genomewide genetic characteristics such as microsatellite DNA loci, particular functional-trait loci (e.g., MHC) or both, and MHC's effects on mate choice remain relatively understudied. Herein, we used 13 microsatellite loci and two MHC class I loci to investigate female mate choice of Chinese alligators (Alligator sinensis) in the semi-natural condition. We also determined correlations between the MHC genotype of breeding males and male reproductive success. We found that MHCheterozygous males harbour a greater reproductive success, which probably is the reason that these males are more preferred by the females than MHC-homozygous males. Furthermore, the MHC class I amino-acid distance and functional distance of true mating pairs were higher compared with those of randomly sampled pairs. Analysis of microsatellites revealed that, despite mate choice, females did not completely avoid inbreeding. These findings are the first evidence of MHC-associated mate choice in Chinese alligators, suggesting that females may adopt different mating strategies after assessing the MHC characteristics of potential mates.
\end{abstract}

\section{Introduction}

Sexual selection has an important role in the evolutionary process by way of maintaining or enhancing population genetic variability (Milinski 2006; Piertney and Oliver 2006; Ruff et al. 2012; Kamiya et al. 2014; Gessner et al. 2017; Santos et al. 2017). Mate choice is a key component of sexual selection, typically manifesting as females selecting preferred males (Sommer 2005). Several studies have demonstrated that females selectively mate with males

Supplementary information The online version of this article (https:// doi.org/10.1038/s41437-018-0177-8) contains supplementary material, which is available to authorised users.

Sheng-Guo Fang

sgfanglab@zju.edu.cn

1 The Key Laboratory of Conservation Biology for Endangered Wildlife of the Ministry of Education and State Conservation Center for Gene Resources of Endangered Wildlife, College of Life Sciences, Zhejiang University, Hangzhou 310058, China

2 Changxing Chinese Alligator Nature Reserve, Changxing 313100, China to increase offspring fitness (Candolin 2003; Penn and Potts 1999), and for direct (e.g., food, shelter and territory) or indirect benefits (high genetic quality) (Candolin 2003; Neff and Pitcher 2005).

In keeping with the importance of indirect benefits, multiple studies have indicated that the genetic characteristics of potential mates determine female mate choice (Strandh et al. 2012; Mariona et al. 2016; Rymesova et al. 2017). The major histocompatibility complex (MHC), which is a highly polymorphic, gene-rich family found in vertebrate genomes, is regarded as a good candidate for studying the genetic basis of mate choice (Klein 1986; Olsson et al. 2003; Sommer 2005; Sin et al. 2015), because MHC genes are crucial to adaptive immunity (Penn and Potts 1999), kin recognition (Manning et al. 1992; Ruff et al. 2012) and mate choice. MHC-associated mate choice has been studied for $>40$ years in various vertebrates, including mammals (Yamazaki et al. 1976; Huchard et al. 2013; Sin et al. 2015; Mariona et al. 2016), fish (Milinski et al. 2005; Agbali et al. 2010), reptiles (Olsson et al. 2003; Jaeger et al. 2016), birds (Juola and Dearborn 2012; Rymesova et al. 2017) and amphibians (Bos et al. 2009). 
Three main hypotheses have been proposed to explain MHC-associated mate choice: good-gene hypothesis (Mays and Hill 2004; Cutrera et al. 2012), heterozygosity advantage hypothesis (Landry et al. 2001) and compatible-gene hypothesis (Zeh and Zeh 1996; Olsson et al. 2003; Puurtinen et al. 2009). According to the good-gene hypothesis, females prefer to mate with males that harbour a particular allele or genotype providing higher heritable qualities and increasing offspring fitness more than the average allele and genotype, in order to resist particular pathogens (Mays and Hill 2004; Penn and Potts 1999; Cutrera et al. 2012). In choosing a mate, females rely on phenotypic indicator traits as a proxy for a preferred genotype (Mays and Hill 2004). This hypothesis finds empirical support in the white-tailed deer (Odocoileus virginianus) (Ditchkoff et al. 2001) and Great Snipe (Gallinago media) (Ekblom et al. 2010).

The heterozygosity advantage hypothesis assumes that males with different MHC alleles are capable of fighting more pathogens than those with few MHC alleles (Landry et al. 2001; Mays and Hill 2004). Males that possess higher overall heterozygosity are generally attractive to females and appear to confer direct benefits through increased vigour (Mays and Hill 2004). In addition, mating with MHCheterozygous males may produce MHC-heterozygous offspring (Landry et al. 2001). MHC-heterozygous males suffer from fewer parasitic infections, thus transmitting a lower parasite load to the offspring (Mariona et al. 2016). Correspondingly, female Talas tuco-tucos (Ctenomys talarum) (Cutrera et al. 2012), Gidgee skinks (Egernia stokesii) (Pearson et al. 2017) and grey wolf (Canis lupus) (Galaverni et al. 2015) tend to select MHC-heterozygous males.

The possibility that compatible-gene hypothesis may boost mate choice is attracting growing attention by researchers. Under this framework, females select males with MHC genotypes that are different from their own (Olsson et al. 2003; Neff and Pitcher 2005; Agbali et al. 2010). Importantly, it might provide a high diversity of MHC genotype (Apanius et al. 1997; Tregenza and Wedell 2000) and/or avoid detrimental effects from inbreeding for the offspring (Grob et al. 1998; Huchard et al. 2013). This hypothesis suggests that individual females can derive different advantages from mating with a given male (Puurtinen et al. 2009). There is sufficient evidence to illustrate mate choice involving gene compatibility, such as in great frigatebirds (Fregata minor) (Juola and Dearborn 2012), grey mouse lemurs (Microcebus murinus) (Schwensow et al. 2008), blue petrels (Halobaena caerulea) (Strandh et al. 2012), greater sac-winged bat (Saccopteryx bilineata) (Santos et al. 2016), Alpine marmots (Marmota marmota) (Ferrandiz-Rovira et al. 2016) and north American raccoons (Procyon lotor) (Santos et al. 2017).
The Chinese alligator (Alligator sinensis) is endemic to the freshwaters of China and is the most endangered of the 23 crocodilian species (Thorbjarnarson and Wang 1999). As a result of habitat loss and fragmentation, the wild population is declining at the rate of $4-6 \%$ every year, and fewer than 130 known individuals are present in the wild (Wang et al. 2011; Zhao et al. 2013). This endangered alligator population were not conserved well until the Changxing Chinese Alligator Nature Reserve (1979) and Anhui Research Center for Chinese Alligator Reproduction (1982) were found, and the number of captive individuals is $\sim 15,000$ at two reserve sites after decades of protection. Many research works have focused on the reproductive biology of the Chinese alligator (Thorbjarnarson et al. 2001; Chen 2003; Zhang et al. 2015; Zhao et al. 2013; Yang et al. 2017). Courtship and mating behaviour are an important part of reproduction (Chen 2003). According to our previous field observations for courtship and mating behaviour during the breeding season, female Chinese alligators show a tendency to mate with certain males (swimming or snout-touching together), while rejecting others (running away or diving into the water). However, no related research has focused on any crocodilian over the past 40 years (Kamiya et al. 2014), and the molecular mechanisms underlying mate choice of the Chinese alligator based on MHC variation remain unclear. Thus, MHC-based research on the Chinese alligator could expand the understanding of mating choice across vertebrates. In addition, as the Chinese alligator is an endangered species, this work could offer a better understanding of the evolutionary mechanisms influencing alligator populations and have great implications for their conservation and management, as well as for the management of other threatened species. Moreover, this study was conducted under semi-natural conditions, which could provide some insight into these cryptic, yet significant, biological phenomena.

In this study, we aimed to elucidate the molecular mechanisms of female mate choice by first investigating whether mating preferences are linked to MHC loci. The study employed 13 microsatellites and two MHC class I loci in the Chinese alligator. We tested three hypotheses based on the good-gene, heterozygosity advantage and compatible-gene hypotheses, respectively: first, females prefer males carrying a specific MHC I gene; second, females prefer heterozygous rather than homozygous males; and, finally, females prefer males that are genetically dissimilar from themselves regarding the MHC class I loci. We also examined whether the Chinese alligator is mates with relatives, and investigated potential correlations between the breeding-male MHC genotype and male reproductive success. 


\section{Materials and methods}

\section{Animal experiment ethics statement}

All blood samples and umbilical cord tissues were collected in accordance with the guidelines approved by the Ethical Committee for Laboratory Animals of Zhejiang University, and all experimental protocols were also approved by the Committee.

\section{Sample collection and DNA extraction}

We obtained blood samples of 182 adult Chinese alligators (123 females and 59 males) from three breeding ponds (Supplementary Table S1) at the Changxing Chinese Alligator Nature Reserve, China $\left(30^{\circ} 93^{\prime} \mathrm{N}, 119^{\circ} 73^{\prime} \mathrm{E}\right)$. The three ponds are separated from each other by a dam and iron net. Hence alligators between the ponds cannot mate, but alligators in the same pond, having no physical barriers, can move freely to mate with each other during the breeding season. Umbilical cord tissues of newborn offspring from 105 clutches were also collected from 2011 to 2017. Tissue samples were stored at $-20^{\circ} \mathrm{C}$ in $98 \%$ ethanol until DNA extraction. Genomic DNA extraction from all samples was conducted using the DNeasy Blood \& Tissue Kit (Shanghai Generay Biotech Co., Ltd., China), following the manufacturer's protocol.

\section{Microsatellite amplification and genotyping}

Genotyping of subjects was performed at 13 neutral microsatellite loci (Supplementary Table S2, Table S3). The poPCR reaction mixture $(10 \mu \mathrm{L})$ contained $1 \mu \mathrm{L}$ of template DNA, $0.3 \mu \mathrm{L}$ of forward and reverse primer, $3.4 \mu \mathrm{L}$ of $2 \times$ Taq PCR Master Mix and $5 \mu \mathrm{L}$ of double-distilled water. The thermocycling protocol was $95^{\circ} \mathrm{C}$ for $5 \mathrm{~min}$, followed by 32 cycles of $94^{\circ} \mathrm{C}$ for $30 \mathrm{~s}, 58^{\circ} \mathrm{C}$ for $30 \mathrm{~s}, 72^{\circ} \mathrm{C}$ for $30 \mathrm{~s}$, and an extension of $72^{\circ} \mathrm{C}$ for $5 \mathrm{~min}$. One of three fluorescent dyes (TAMRE, HEX or FAM) was used to label the $5^{\prime}$ end of microsatellite forward primers. Negative controls included $1 \mu \mathrm{L}$ of double-distilled water instead of the DNA template. Analysis of PCR products was conducted using an ABI 3130 Genetic Analyzer (Applied Biosystems Inc.). Allele size was determined using Gene Marker version 1.7.0, combined with visual analysis. To ensure accuracy in microsatellite genotyping, amplification and analysis were performed twice across all individuals and 1\% genotyping error rate was allowed.

\section{MHC amplification and genotyping}

Two MHC class I loci, I1327exon3 and I20exon2 (I1327e3: two alleles and I20e2: two alleles; Supplementary Table S2,
Table S3), were amplified in a $10 \mu \mathrm{L}$ reaction mixture containing $1 \mu \mathrm{L}$ of template DNA, $0.3 \mu \mathrm{L}$ of each primer, $3.4 \mu \mathrm{L}$ of $2 \times$ Taq PCR Master Mix and $5 \mu \mathrm{L}$ of doubledistilled water. The PCR reaction protocol was $95^{\circ} \mathrm{C}$ for $5 \mathrm{~min}, 32$ cycles of $94^{\circ} \mathrm{C}$ for $30 \mathrm{~s}, 60^{\circ} \mathrm{C}$ for $30 \mathrm{~s}, 72^{\circ} \mathrm{C}$ for $30 \mathrm{~s}$ and $72^{\circ} \mathrm{C}$ for $5 \mathrm{~min}$.

We used the PCR-single-strand conformation polymorphism (SSCP) technique to genotype each individual. In the SSCP process, each PCR product was added to $5 \mu \mathrm{L}$ of $2 \times$ loading buffer $(0.025 \%$ xylene-cyanol, $0.025 \%$ bromophenol blue, $10 \mathrm{~mm}$ EDTA (ethylenediaminetetraacetic acid) and $98 \%$ formamide) and denatured at $95^{\circ} \mathrm{C}$ for $5 \mathrm{~min}$, chilled on ice and then loaded onto a $12 \%$ non-denaturing polyacrylamide (Bio-Rad) gel (acrylamide: $N, N^{\prime}$-methylenebis acrylamide $=37.5: 1)$. Sequences were separated in $0.5 \times \mathrm{TBE}$ (tris-borate buffer) running buffer on the Dcode System (Bio-Rad) for $6.5 \mathrm{~h}$ at $10^{\circ} \mathrm{C}$ and $150 \mathrm{~V}$. Finally, the gel was subjected to a 20 -min treatment with $10 \%$ acetic acid, washed with $\mathrm{dH}_{2} \mathrm{O}$ and silver-stained to visualise the bands. The PCR-SSCP process was repeated at each locus to ensure a stable and consistent banding pattern.

\section{Parentage analysis}

We conducted maximum-likelihood-based paternity analysis using Cervus 3.0.6 (Kalinowski et al. 2007). An error rate of $1 \%$ for mistyping, and for null allele or mutation was allowed. Paternity analysis was done using 95\% confidence levels. In addition, the analysis was repeated in Colony 2.0 (Jones and Wang 2010) to reach $95 \%$ consistency between the two methods. Paternal genotypes for the known genotype of maternal-offspring clutches were reconstructed using Colony 2.0. MHC genotypes were used to examine the parentage results according to Mendel's law of inheritance.

\section{Analysis of male reproductive success}

The number of offspring in each clutch was considered the male reproductive success. We used the generalised linear mixed model with a Poisson distribution (logarithmic link) to assess the effect of male MHC genotype (MHC-heterozygote vs. MHC-homozygote) on reproductive success. The response variable was offspring number and the explanatory variable was defined as binary (" 0 " representing male MHC-homozygote and " 1 " MHC-heterozygote). The model was built using the glmer function of the LME4 package in $\mathrm{R}$ language using the following formula:

glmer(Offspring_number zygosity_status $+(1 \mid$ paternal_ID $)$, family $=\operatorname{poisson}(\operatorname{link}=\log ))$ 


\section{Statistical analysis}

\section{Mate choice hypotheses}

Estimator used to test good-gene hypothesis Each locus has two alleles. The male individual MHC allele frequency (AF) of each locus was used to assess whether females selected mates based on good gene.

Estimators used to test heterozygosity advantage hypothesis Three estimators were used: (1) male individual microsatellite standardised heterozygosity ( $\mathrm{SH}$; Coltman et al. 1999), (2) $d^{2}$ (genetic similarity between two alleles) and (3) male individual MHC heterozygosity (Ho). SH was calculated using the library Genhet of $\mathrm{R}$ language. Heterozygosity by locus (HL; Aparicio et al. 2006) and internal relatedness (IR; Amos et al. 2001) were also calculated as additional microsatellite heterozygosity indices, because these measures are highly correlated (all $R^{2}>0.95$; Supplementary Table S4); only SH results are shown. Genetic similarity was calculated as $d^{2}=1 / n \Sigma^{n}\left(i_{\mathrm{a}}-i_{\mathrm{b}}\right)^{2}$, where $i_{\mathrm{a}}$ and $i_{\mathrm{b}}$ are the lengths of repeat motifs in the two alleles and $n$ is the total microsatellite loci number. Ho was calculated as the proportion of heterozygous males among breeding males. SH and $d^{2}$ were used to test whether female mate choice was based on genome-wide characteristics, while Ho was tested on the basis of MHC class I loci.

Estimators used to test compatible-gene hypothesis Three pairwise estimators based on MHC class I were used: (1) allele sharing (Nsa) between pairs, (2) pairwise amino-acid distance (AAdist) and (3) pairwise amino-acid functional distance (AAfunc.dist). Values for allele sharing ranged from 0 to 2 (no allele, one allele or two alleles shared). The amino-acid distance of MHC alleles was calculated using MEGA 7.0, with the formula AAdist $=\mathrm{DAB}+\mathrm{DAb}+$ $\mathrm{DaB}+\mathrm{Dab}$, where $\mathrm{A}$, a, B, b represent the four alleles carried by pairs (Landry et al. 2001). For AAfunc.dist, the physiochemical properties of each amino acid were represented by five z-descriptors (Sandberg et al. 1998); a matrix between alleles was constructed and the Euclidian distance of all amino acids was calculated (Agbali et al. 2010; Huchard et al. 2013). The formula used to calculate AAfunc.dist is similar to the one used for AAdist.

\section{Pairwise relatedness}

Pairwise relatedness between mating partners was calculated using the Queller and Goodnight relatedness estimator ( $R_{\mathrm{qg}}$; Queller and Goodnight 1989) in Co-ancestry (Wang 2011). Wang's estimator (Wang 2002), as well as Lynch and Ritland estimator (Lynch and Ritland 1999), was also used. As the three neutral estimators of relatedness were highly correlated (all $R^{2}>0.79$; Supplementary Table S5), only $R_{\mathrm{qg}}$ results are shown.

\section{Randomisation tests}

The random pairs were generated by sampling with replacement using Monte Carlo simulations. As the three ponds had different mating pairs, stratified sampling was performed. The details are as follows: a female and a male were randomly selected from the same breeding pool for pairing; the number of random-sampling pairs in each pond was consistent with the number of true mating pairs. The total number of random pairs from the three ponds was regarded as the total number of true mating pairs, and was used to calculate the mean value of the microsatellite and MHC genetic indices. We repeated the above method 9999 times to derive a distribution. Then we used a two-tailed test (significance set to $P<0.05$ ) to compare the mean observed values of the true mating pairs with the sampling frequency distribution. Observed values were significant if they fell outside of the $95 \%$ confidence interval (CI). Statistical analyses and graphical representations were performed using Python (numpy, pandas, scipy and matplotlib modules).

\section{Results}

\section{Parentage analysis}

In all, 182 adults and 1684 offspring were genotyped successfully using both 13 microsatellite loci and 2 MHC class I loci. We reconstructed 27 paternal genotypes. Eighty-two parental pairs were assigned using 13 microsatellite loci. MHC genotypes were in keeping with Mendel's law of inheritance, confirming the reliability of parentage analysis.

\section{No evidence for good-gene hypothesis}

A comparison of observed MHC allele frequency (AF) per locus of breeding males and the the frequency distribution of randomly selected males revealed no significant difference (observed value $_{\text {I1327e3 }} \mathrm{AF}=1.268, \quad P=0.252$; observed value $_{\mathrm{I} 20 \mathrm{e} 2} \mathrm{AF}=0.683, P=0.837$, Supplementary Figure S1).

\section{Preference mating with heterozygous males}

The $d^{2}$ and SH (based on 13 microsatellites) of breeding males were compared with the distribution of randomly selected males. Breeding males and randomly sampled males did not differ significantly in $d^{2}$ (observed value $d^{2}=$ 9.437, $P=0.691$, Fig. 1a) or $\mathrm{SH}$ (observed value $\mathrm{SH}=$ 

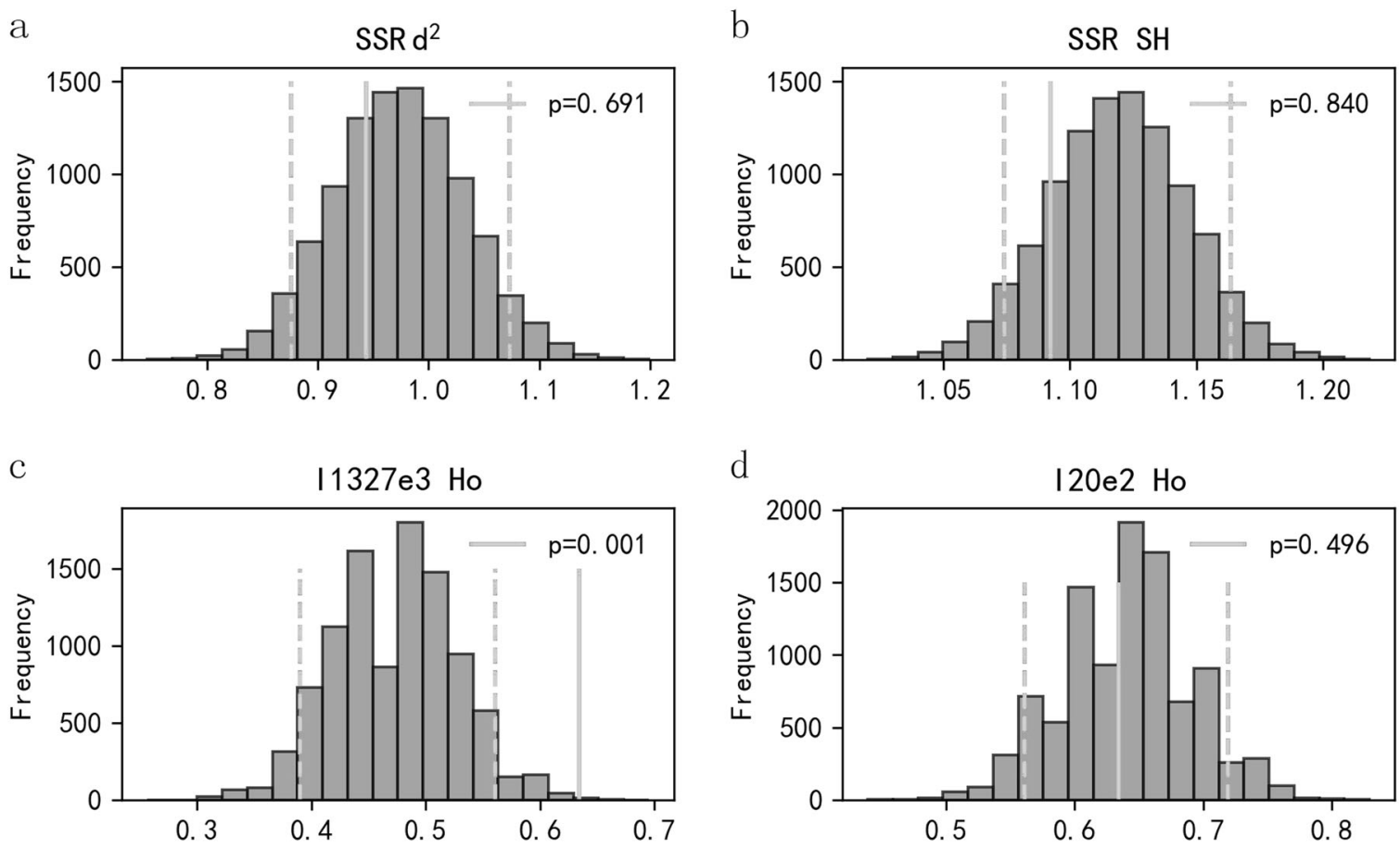

Fig. 1 MHC-dependent mate choice tested with Monte Carlo simulations. Frequency distributions of mean $d^{2}$, standardised heterozygosity (SH) and MHC heterozygosity (Ho), generated from 9999 Monte Carlo simulations of potential males (grey bars) compared with the

1.092, $P=0.840$, Fig. 1 b). In contrast, breeding males had a higher Ho frequency for MHC I1327e3 locus than randomly sampled males (observed value $\mathrm{II327e3}_{\mathrm{H}} \mathrm{Ho}=0.634, P$ $=0.001$, Fig. 1c), but not for I20e2 locus (observed value $_{\mathrm{I} 20 \mathrm{e} 2} \mathrm{Ho}=0.634, P=0.496$, Fig. 1d).

\section{MHC-compatible gene mating}

True mating pairs had significantly higher AAdist for I1327e 3 locus than randomly sampled pairs (observed value I1327e3 AAdist $=0.0218, P=0.031$, Fig. 2a). Pairwise AAfunc.dist for the I1327e 3 locus also differed significantly (observed value $_{11327 \mathrm{e} 3}$ AAfunc.dist $=0.242, \quad P=0.031$, Fig. 2c). Neither AAdist nor AAfunc.dist differed significantly between true mating pairs and randomly sampled pairs for the I20e2 locus (observed value ${ }_{\mathrm{I} 20 \mathrm{e} 2}$ AAfunc.dist $=0.0245, P=0.730$, Fig. $2 \mathrm{~b}$; observed value ${ }_{\mathrm{I} 20 \mathrm{e} 2}$ AAfunc. dist $=0.322, P=0.730$, Fig. 2d). Nsa per locus between true mating pairs and randomly selected pairs did not differ significantly (observed value I1327e3 Nsa $=1.329, P=$ 0.389 , Fig. 2e; observed value ${ }_{\text {I20e2 }} \mathrm{Nsa}=1.463, P=0.125$, Fig. 2f).

\section{No obvious inbreeding avoidance}

We compared Queller and Goodnight relatedness between true mating pairs and randomly sampled pairs and found no

observed values (solid vertical lines). Two-tailed 95\% CI (dashed lines) indicate cutoffs for significant departures from randomly sampled males. a $d^{2}$; b SH; c Ho of I1327e3 loci; d Ho of I20e2 loci

significant difference in pairwise relatedness (observed value $R_{\mathrm{qg}}=0.046, P=0.26$, Fig. 3), indicating that females do not avoid mating with close relatives.

\section{Male MHC genotype and reproductive success}

We investigated whether male MHC genotype exerts an effect on the number of offspring. Statistical significance was found for a correlation between male MHC genotype at I1327e 3 locus and the number of offspring. In other words, heterozygous males had significantly higher reproductive success than homozygous males $(P=0.044$, Fig. 4$)$.

\section{Discussion}

In our study, we found evidence that female Chinese alligators tended to mate with males exhibiting MHC heterozygosity and genetic compatibility. The lack of heterozygosity advantage among neutral markers (HS and $d^{2}$; Fig. 1a, b) further suggested that MHC may be the target gene of female mate choice. The preference for MHC heterozygotes is in agreement with previous findings for wiretailed manakin (Pipra filicauda) (Ryder et al. 2010), scarlet rosefinch (Carpodacus erythrinus) (Promerova et al. 2011), common lizard (Zootoca vivipara) (Laloi et al. 2011) and Talas tuco-tucos (Cutrera et al. 2012). Females may exhibit 
a

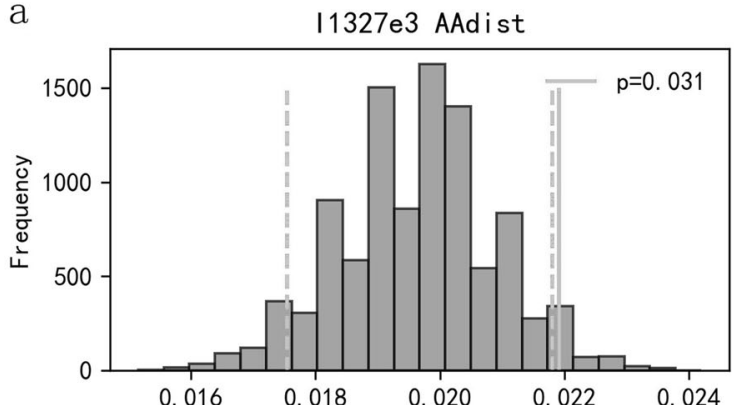

C

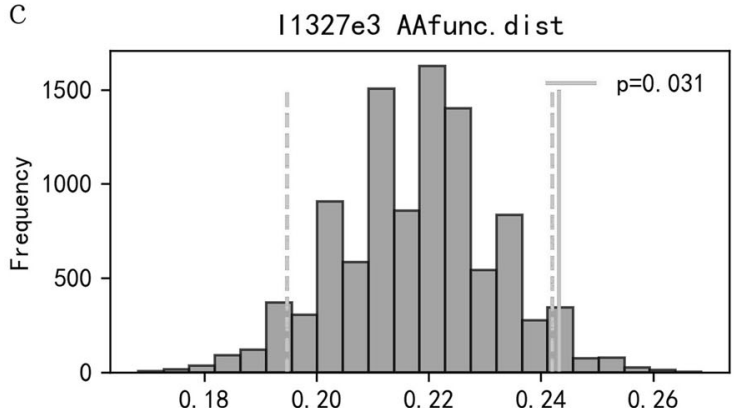

e

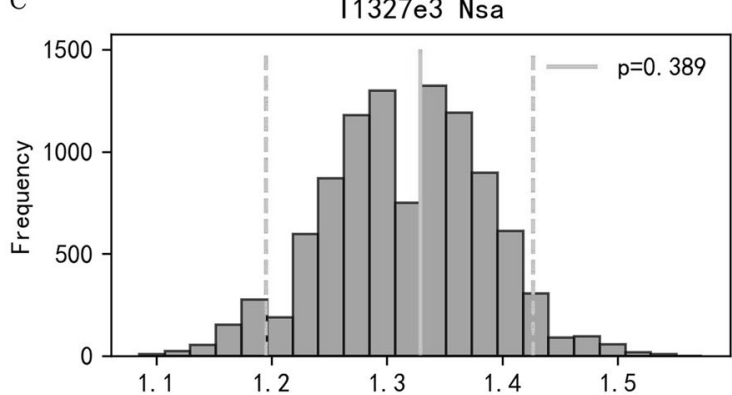

Fig. 2 MHC-dependent mate choice tested with Monte Carlo simulations. Frequency distributions of mean MHC allele sharing (Nsa), pairwise amino-acid distance (AAdist) and pairwise amino-acid functional distance (AAfunc.dist), respectively, generated from 9999 Monte Carlo simulations of randomly sampled pairs (grey bars) compared with the observed value of true mating pairs (solid vertical

such a preference because heterozygosity is positively correlated with individual adaptability. For the Chinese alligators, the males provid no direct material benefits such as food, nest defence behaviours or parental care for the offspring (Chen 2003); hence the female may select heterozygous males in order to increase the genetic quality of offspring (Landry et al. 2001). In general, heterozygous males appear to be more capable of providing the indirect (fitness) benefits to females and their offspring (Mays and Hill 2004; Roberts et al. 2006; Mariona et al. 2016).

In support of the above-mentioned observation, we found that MHC-heterozygous males had higher reproductive success than MHC-homozygous males (Fig. 4). Galaverni et al. (2015) showed that the fitness values (average litter

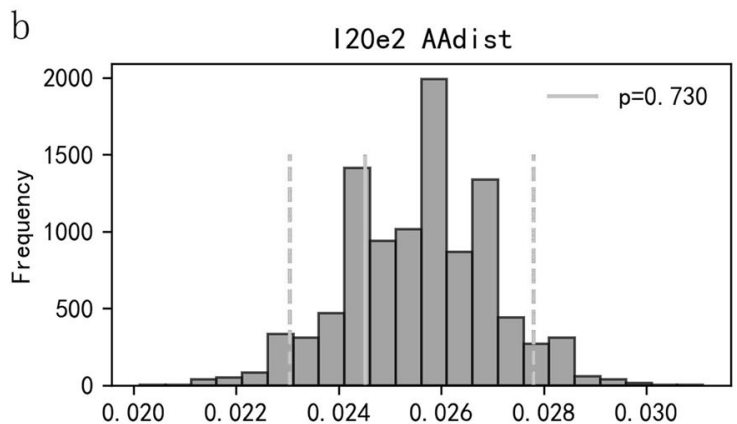

d
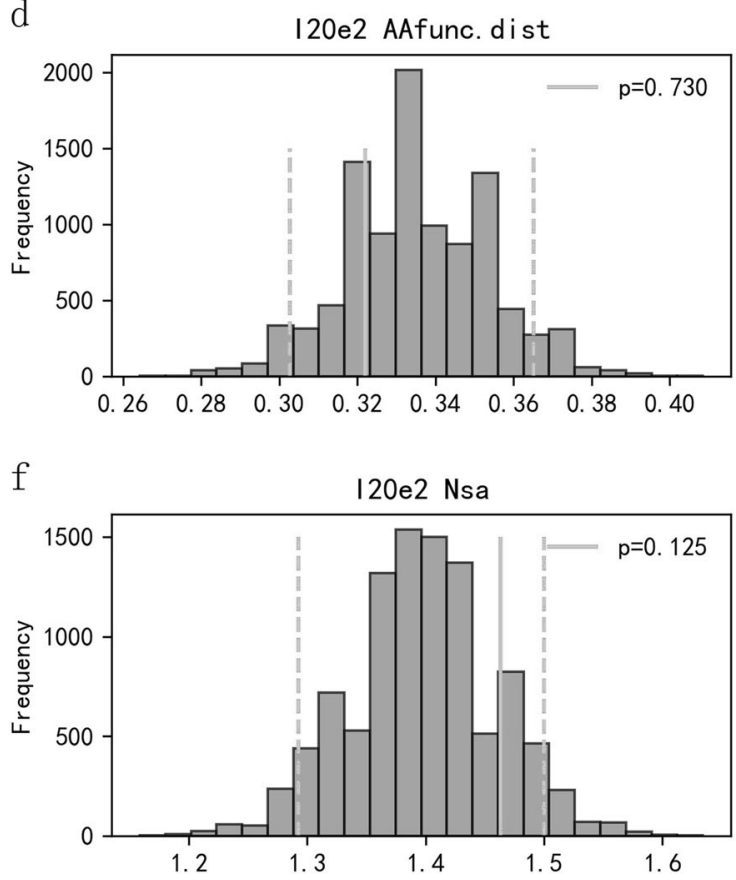

lines). Two-tailed $95 \%$ CI values (dashed lines) indicate cutoffs for significant departures from random sampling pairs. a AAdist of I1327e3 loci; b AAdist of I20e2 loci; c AAfunc.dist of I1327e3 loci; d AAfunc.dist of I20e2 loci; e Nsa of I1327e3 loci; and f Nsa of I20e2 loci

size) of grey wolf were positively correlated to the average heterozygosity of breeders at MHC loci. A similar result has also been reported for the Arctic Charr (Salvelinus alpinus) (Skarstein et al. 2005). One potential explanation for this higher performance of MHC-heterozygous males is a greater diversity of antigen-presenting molecules due to dissimilar MHC alleles, leading to broader pathogen resistance (Agbali et al. 2010). Consequently, females preferentially mate with genetically dissimilar males to increase the likelihood of producing heterozygous offspring (Skarstein et al. 2005).

The compatible-gene hypothesis was supported by the result that true mating pairs had higher pairwise amino-acid distance (Fig. 2a) and amino-acid function distance (Fig. 2c) 


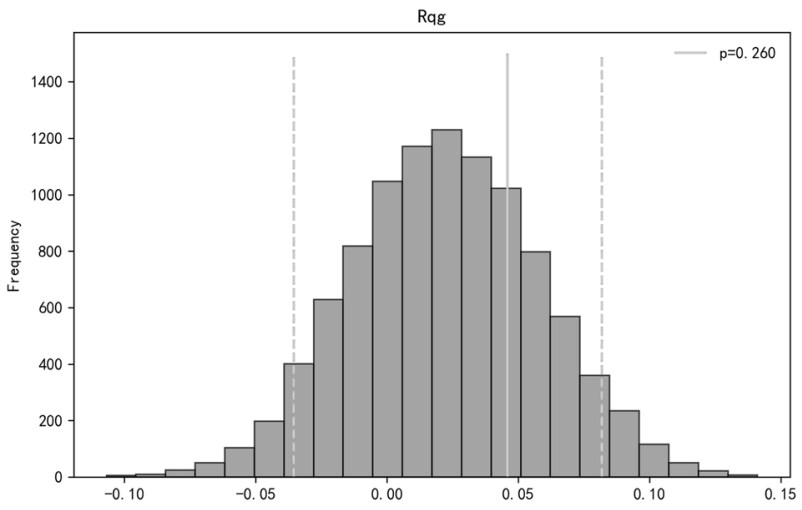

Fig. 3 Effect of mate choice on pairwise relatedness. Frequency distributions of mean Queller and Goodnight relatedness (Rqg) generated from 9999 Monte Carlo simulations of randomly sampled pairs (grey bars) compared with the observed value of true mating pairs (solid vertical lines). Two-tailed 95\% CI values (dashed lines) indicate cutoffs for significant departures from randomly sampled pairs

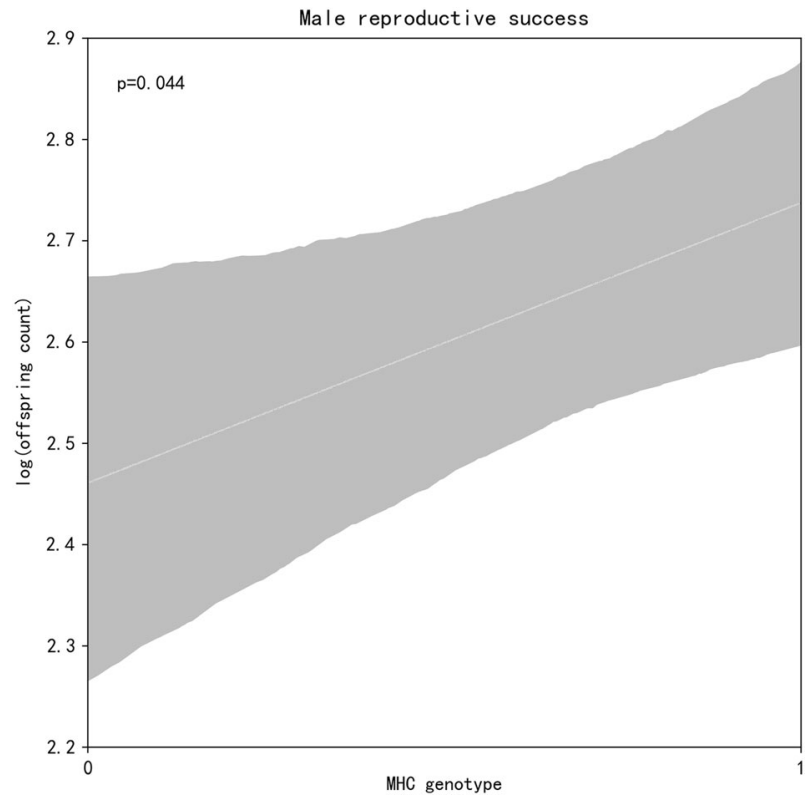

Fig. 4 The relationship between offspring count and male MHC genotype tested with generalised linear mixed model (GLMM). Shaded areas represent two-tailed 95\% CI, which were generated by 10,000 bootstraps

than randomly sampled pairs at the I1327e 3 locus. Female Chinese alligators choose males with compatible genetic characteristics that may be beneficial for several reasons. First, diseases due to external and internal parasites are prevalent in captive Chinese alligators (Zhao et al. 2015); this may be an alternative way to increase the MHC diversity of the offspring, which could improve their resistance to various pathogens or diseases (Apanius et al. 1997; Neff and Pitcher 2005). Second, our results showed that females did not avoid inbreeding (Fig. 3). The kind of female mate choice observed here is in accordance with other previous studies conducted both in the laboratory (sticklebacks, Gasterosteus aculeatus: Milinski et al. 2005; Chinese rose bitterling, Rhodeus ocellatus: Agbali et al. 2010; mandrill, Mandrill ussphinx: Setchell et al. 2010) and in the field (sand lizard: Olsson et al. 2003; Schwensow et al. 2008; grey mouse lemurs: Huchard et al. 2013; great sac-winged bats: Santos et al. 2016). For example, a study of wild grey mouse lemurs showed that the amino-acid distance of fathers to females is higher than that of randomly assigned males (Schwensow et al. 2008).

In contrast to our findings, some species show no evidence of MHC-dissimilar mating, including great tits (Parus major) (Sepil et al. 2015), great reed warbler (Acrocephalus arundinaceus) (Westerdahl 2004) and common yellowthroats (Geothlypis trichas) (Bollmer et al. 2012). Still others actually exhibit a preference for similar MHC, such as house sparrows (Passer domesticus) (Bichet et al. 2014), European badgers (Meles meles) (Sin et al. 2015) and fish (Poecilia reticulate) (Clelia et al. 2015). In addition, there are conflicting reports about MHC-based mate choice for species such as Atlantic salmon (Salmo salar) (Consuegra and de Leaniz 2008; Promerova et al. 2017).

Preferential mating for heterozygosity advantage and compatible genes is not mutually exclusive, as females can simultaneously assess both characteristics according to a hierarchical, nested rule (Mays and Hill 2004). Research on mice supports this mechanism: female mice first favoured certain males based on urinary scent marks, and then selected males with the greatest MHC dissimilarity among the initially preferred individuals (Roberts and Gosling 2003). For Chinese alligators, genome sequence has unravelled that they harbour a genetic basis of a robust sensory system (Wan et al. 2013). Therefore, female Chinese alligators may select males with high or medium heterozygosity, and then fine-tune the choice by considering genetic compatibility. Similar findings have also been reported in giant panda (Ailuropoda melanoleuca) (Zhu 2014) and golden snub-nosed monkey (Rhinopithecus roxellana) (Song 2016).

In the semi-natural condition the alligators congregate because of bellowing behaviour during the mating season, so the chances of the female searching for and selecting the potential mating male are high (Wang et al. 2006). Previous studies have shown that MHC has a role in kin recognition and inbreeding avoidance (Manning et al. 1992; Grob et al. 1998; Ruff et al. 2012). However, here we found that Chinese alligator females did not avoid close relatives when selecting males (Fig. 3). This finding is surprising given the widely acknowledged adaptive importance of inbreeding avoidance (Pusey 1996; Bull and Cooper 1999; Hu et al. 2017; Huchard et al. 2017). In our study, 182 adult alligators are from only 11 wild founders, suggesting that breeding with close relatives is unavoidable. Thus, being left with no other suitable potential mates, the females have 
no choice but to mate with relatives to maximise the fitness and survival rate of offspring, regardless of the risk of inbreeding depression. Multiple studies have reported that inbreeding avoidance is absent if the benefits outweigh the costs of inbreeding avoidance (Kokko and Ots 2006; Jamieson et al. 2009; Szulkin et al. 2013; Huchard et al. 2017). For example, the dispersal behaviour of captive populations is limited and encounters between close relatives are easy to occur; hence, avoidance of close breeding may result in delaying or missing opportunities for breeding (Keller and Arcese 1998). Studies also show that mating with a close partner could be advantageous, as it increases the parent's inclusive fitness (Waser et al. 1986; Kokko and Ots 2006). However, for many threatened species, it is impossible to have a natural 'built-in' mechanism for avoiding inbreeding (Jamieson et al. 2009).

Our study has some notable limitations. First, although we found evidence that female Chinese alligators prefer males with heterozygous and genetically dissimilar MHC I loci, the direct phenotypic traits for recognition of partners remain unknown and are difficult to be observed. Second, the number and density of the wild population are, respectively, less and scattered, which may make it more or less likely that the pattern of mate choice is different from that of the semi-natural population in our study. Third, although our results show that MHC-heterozygous males have increased reproductive success (offspring number) compared with MHC-homozygous males, we cannotrule out the possibility of the effect of potential confounding factors such as nesting environment or raining on the reproductive success.

In conclusion, this is the first study to describe MHCassociated mate choice in any crocodilian in semi-natural condition. Our data support the heterozygosity advantage and compatible-gene hypotheses, which contributes to our knowledge of MHC-based mate choice in reptiles. However, our study gives rise to additional unsolved questions regarding MHC-mediated mate choice, which deserves future study in this endangered species. For instance, colour, olfaction, acoustics and other morphological traits are reliable signals of MHC genes (Penn 2002; Olsson et al. 2003; Overath et al. 2014; Garamszegi et al. 2018), suggesting fruitful avenues of further research to understand whether such traits also reflect MHC in Chinese alligators. Intriguingly, genome sequence analysis has demonstrated robust olfactory, visual and aural systems for Chinese alligators (Wan et al. 2013). These phenotypic cues may be the means through which Chinese alligators recognise the appropriate $\mathrm{MHC}$ identity of potential mates.

\section{Data archiving}

Sequences have been submitted to GenBank under accession numbers MK270510, MK270511, MK270512 and
MK270513. MHC data are available from the Dryad Digital Repository: https://doi.org/10.5061/dryad.vq05124.

Acknowledgements We express our gratitude to the staff at the Changxing Yinjiabian Chinese Alligator Nature Reserve for kind assistance with sampling, in particular Wei-Qiang Zou, Da-Bin Ren and Ju-Min $\mathrm{Xu}$. This work was supported by grants from the National Natural Science Foundation of China (31470438 and 31530087), the National Key Programme (2016YFC0503200) from the Ministry of Science and Technology of China, a special grant from the State Forestry Administration and the Fundamental Research Funds for the Central Universities of China.

Conflict of interest The authors declare that they have no conflict of interest.

Publisher's note: Springer Nature remains neutral with regard to jurisdictional claims in published maps and institutional affiliations.

Open Access This article is licensed under a Creative Commons Attribution 4.0 International License, which permits use, sharing, adaptation, distribution and reproduction in any medium or format, as long as you give appropriate credit to the original author(s) and the source, provide a link to the Creative Commons license, and indicate if changes were made. The images or other third party material in this article are included in the article's Creative Commons license, unless indicated otherwise in a credit line to the material. If material is not included in the article's Creative Commons license and your intended use is not permitted by statutory regulation or exceeds the permitted use, you will need to obtain permission directly from the copyright holder. To view a copy of this license, visit http://creativecommons. org/licenses/by/4.0/.

\section{References}

Agbali M, Reichard M, Bryjova A, Bryja J, Smith C (2010) Mate choice for nonadditive genetic benefits correlate with MHC dissimilarity in the rose bitterling (Rhodeus ocellatus). Evolution 64:1683-1696

Amos W, Wilmer JW, Fullard K, Burg TM, Croxall JP, Bloch D et al. (2001) The influence of parental relatedness on reproductive success. Proc Biol Sci 268:2021-2027

Apanius V, Penn D, Slev PR, Ruff LR, Potts WK (1997) The nature of selection on the major histocompatibility complex. Crit Rev Immunol 17:179-224

Aparicio JM, Ortego J, Cordero PJ (2006) What should we weigh to estimate heterozygosity, alleles or loci? Mol Ecol 15:4659-4665

Bichet C, Penn DJ, Moodley Y, Dunoyer L, Cellier-Holzem E, Belvalette $M$ et al. (2014) Females tend to prefer genetically similar mates in an island population of house sparrows. BMC Evol Biol $14: 47-58$

Bollmer JL, Dunn PO, Freemangallant CR, Whittingham LA (2012) Social and extra-pair mating in relation to major histocompatibility complex variation in common yellowthroats. Proc Biol Sci 279:4778-4785

Bos DH, Williams RN, Gopurenko D, Bulut Z, Dewoody JA (2009) Condition-dependent mate choice and a reproductive disadvantage for MHC-divergent male tiger salamanders. Mol Ecol 18:3307-3315

Bull CM, Cooper SJB (1999) Relatedness and avoidance of inbreeding in the lizard. Tiliqua rugosa Behav Ecol Sociobiol 46:367-372

Candolin U (2003) The use of multiple cues in mate choice. Biol Rev $78: 575-595$ 
Chen BH (2003) Research on the Chinese Alligator. Shanghai Scientific and Technological Education Publishing House, Shanghai, China

Clelia G, Leonardo C, Andrea P (2015) MHC-similarity and sexual selection: different doesn't always mean attractive. Mol Ecol 24:1996-2004

Coltman DW, Pilkington JG, Smith JA, Pemberton JM (1999) Parasite-mediated selection against inbred soay sheep in a freeliving island population. Evolution 53:1259-1267

Consuegra S, de Leaniz CG (2008) MHC-mediated mate choice increases parasite resistance in salmon. Proc Biol Sci 275:1397-1403

Cutrera AP, Fanjul MS, Zenuto RR (2012) Females prefer good genes: MHC-associated mate choice in wild and captive tuco-tucos. Anim Behav 83:847-856

Ditchkoff SS, Lochmiller RL, Masters RE, Hoofer SR, Van Den Bussche RA (2001) Major-histocompatibility-complexassociated variation in secondary sexual traits of white-tailed deer (Odocoileus virginianus): evidence for good-genes advertisement. Evolution 55:616-625

Ekblom R, Saether SA, Fiske P, Kalas JA, Hoglund J (2010) Balancing selection, sexual selection and geographic structure in MHC genes of Great Snipe. Genetica 138:453-461

Ferrandiz-Rovira M, Allaine D, Callait-Cardinal MP, Cohas A (2016) Mate choice for neutral and MHC genetic characteristics in Alpine marmots: different targets in different contexts? Ecol Evol 6:4243-4257

Galaverni M, Caniglia R, Milanesi P, Lapalombella S, Fabbri E, Randi E (2015) Choosy wolves? Heterozygote advantage but no evidence of MHC-based disassortative mating. J Hered 107:134-142

Garamszegi LZ, Zagalska-Neubauer M, Canal D, Blazi G, Laczi M, Nagy G et al. (2018) MHC-mediated sexual selection on birdsong: Generic polymorphism, particular alleles and acoustic signals. Mol Ecol 27:2620-2633

Grob B, Knapp LA, Martin RD, Anzenberger G (1998) The major histocompatibility complex and mate choice: inbreeding avoidance and selection of good genes. Exp Clin Immunogenet 15:119-129

Gessner C, Nakagawa S, Zavodna M, Gemmell NJ (2017) Sexual selection for genetic compatibility: the role of the major histocompatibility complex on cryptic female choice in Chinook salmon (Oncorhynchus tshawytscha). Heredity 118:442-452

Hu YB, Nie YG, Wei W, Ma TX, Van Horn R, Zheng XG et al. (2017) Inbreeding and inbreeding avoidance in wild giant pandas. Mol Ecol 26:5793-5806

Huchard E, Baniel A, Schliehe-Diecks S, Kappeler PM (2013) MHCdisassortative mate choice and inbreeding avoidance in a solitary primate. Mol Ecol 22:4071-4086

Huchard E, Schliehe-Diecks S, Kappeler PM, Kraus C (2017) The inbreeding strategy of a solitary primate, Microcebus murinus. J Evol Biol 30:128-140

Jaeger CP, Duvall MR, Swanson BJ, Phillips CA, Dreslik MJ, Baker SJ et al. (2016) Microsatellite and major histocompatibility complex variation in an endangered rattlesnake, the Eastern Massasauga (Sistrurus catenatus). Ecol Evol 6:3991-4003

Jamieson IG, Taylor SS, Tracy LN, Kokko H, Armstrong DP (2009) Why some species of birds do not avoid inbreeding: insights from New Zealand robins and saddlebacks. Behav Ecol 20:575-584

Jones OR, Wang JL (2010) COLONY: a program for parentage and sibship inference from multilocus genotype data. Mol Ecol Resour 10:551-555

Juola FA, Dearborn DC (2012) Sequence-based evidence for major histocompatibility complex-disassortative mating in a colonial seabird. Proc Biol Sci 279:153-162

Kalinowski ST, Taper ML, Marshall TC (2007) Revising how the computer program CERVUS accommodates genotyping error increases success in paternity assignment. Mol Ecol 16:1099-1106

Kamiya T, O’Dwyer K, Westerdahl H, Senior A, Nakagawa S (2014) A quantitative review of MHC-based mating preference: the role of diversity and dissimilarity. Mol Ecol 23:5151-5163

Keller LF, Arcese P (1998) No evidence for inbreeding avoidance in a natural population of song sparrows (Melospiza melodia). Am Nat 152:380-392

Klein J (1986) Natural history of the major histocompatibility complex. Wiley and Sons, New York City, New York

Kokko H, Ots I (2006) When not to avoid inbreeding. Evolution 60:467-475

Laloi D, Eizaguirre C, Federici P, Massot M (2011) Female choice for heterozygous mates changes along successive matings in a lizard. Behav Process 88:149-154

Landry C, Garant D, Duchesne P, Bernatchez L (2001) 'Good genes as heterozygosity': the major histocompatibility complex and mate choice in Atlantic salmon (Salmo salar). Proc Biol Sci 268:1279-1285

Lynch M, Ritland K (1999) Estimation of pairwise relatedness with molecular markers. Genetics 152:1753-1766

Manning CJ, Wakeland EK, Potts WK (1992) Communal nesting patterns in mice implicate MHC genes in kin recognition. Nature 360:581-583

Mariona FR, Dominique A, Marie-Pierre CC, Aurélie C (2016) Mate choice for neutral and MHC genetic characteristics in Alpine marmots: different targets in different contexts? Ecol Evol 6:4243-4257

Mays Hl, Hill GE (2004) Choosing mates: good genes versus genes that are a good fit. Trends Ecol Evol 19:554-559

Milinski M, Griffiths S, Wegner KM, Reusch TBH, Haas-Assenbaum A, Boehm T (2005) Mate choice decisions of stickleback females predictably modified by MHC peptide ligands. Proc Natl Acad Sci USA 102:4414-4418

Milinski M (2006) The major histocompatibility complex, sexual selection, and mate choice. Annu Rev Ecol Evol Syst 37:159-186

Neff BD, Pitcher TE (2005) Genetic quality and sexual selection: an integrated framework for good genes and compatible genes. Mol Ecol 14:19-38

Olsson M, Madsen T, Nordby J, Wapstra E, Ujvari B, Wittsell H (2003) Major histocompatibility complex and mate choice in sand lizards. Proc Biol Sci 270:S254-S256

Overath P, Sturm T, Rammensee HG (2014) Of volatiles and peptides: in search for MHC-dependent olfactory signals in social communication. Cell Mol Life Sci 71:2429-2442

Pearson SK, Godfrey SS, Schwensow N, Bull CM, Gardner MG (2017) Genes and group membership predict gidgee skink (Egernia stokesii) reproductive pairs. J Hered 108:369-378

Penn DJ (2002) The scent of genetic compatibility: sexual selection and the major histocompatibility complex. Ethology 108:1-21

Penn DJ, Potts WK (1999) The evolution of mating preferences and major histocompatibility complex genes. Am Nat 153:145-164

Piertney SB, Oliver MK (2006) The evolutionary ecology of the major histocompatibility complex. Heredity 96:7-21

Promerova M, Alavioon G, Tusso S, Burri R, Immler S (2017) No evidence for MHC class II-based non-random mating at the gametic haplotype in Atlantic salmon. Heredity 118:563-567

Promerova M, Vinkler M, Bryja J, Polakova R, Schnitzer J, Munclinger P et al. (2011) Occurrence of extra-pair paternity is connected to social male's MHC-variability in the scarlet rosefinch Carpodacus erythrinus. J Avian Biol 42:5-10

Pusey A (1996) Inbreeding avoidance in animals. Trends Ecol Evol 11:201-206

Puurtinen M, Ketola T, Kotiaho J (2009) The good-genes and compatible-genes benefits of mate choice. Am Nat 174:741-752 
Queller DC, Goodnight KF (1989) Estimating relatedness using genetic marker. Evolution 43:258-275

Roberts SC, Gosling LM (2003) Genetic similarity and quality interact in mate choice decisions by female mice. Nat Genet 35:103-106

Roberts SC, Hale ML, Petrie M (2006) Correlations between heterozygosity and measures of genetic similarity: implications for understanding mate choice. J Evol Biol 19:558-569

Ruff JS, Nelson AC, Kubinak JL, Potts WK (2012) MHC signaling during social communication. Adv Exp Med Biol 738:290-313

Ryder TB, Tori WP, Blake JG, Loiselle BA, Parker PG (2010) Mate choice for genetic quality: a test of the heterozygosity and compatibility hypotheses in a lek-breeding bird. Behav Ecol 21:203-210

Rymesova D, Kralova T, Promerova M, Bryja J, Tomasek O, Svobodova J et al (2017) Mate choice for major histocompatibility complex complementarity in a strictly monogamous bird, the grey partridge (Perdix perdix). Front Zool 14, 9

Sandberg M, Eriksson L, Jonsson J, Sjostrom M, Wold S (1998) New chemical descriptors relevant for the design of biologically active peptides. A multivariate characterization of 87 amino acids. J Med Chem 41:2481-2491

Santos PSC, Courtiol A, Heidel AJ, Hoener OP, Heckmann I, Nagy M et al. (2016) MHC-dependent mate choice is linked to a trace-amine-associated receptor gene in a mammal. Sci Rep 6:38490

Santos PSC, Michler FU, Sommer S (2017) Can MHC-assortative partner choice promote offspring diversity? A new combination of MHC-dependent behaviors among sexes in a highly successful invasive mammal. Mol Ecol 26:2392-2404

Schwensow N, Eberle M, Sommer S (2008) Compatibility counts: MHC-associated mate choice in a wild promiscuous primate. Proc Biol Sci 275:555-564

Sepil I, Radersma R, Santure AW, De Cauwer I, Slate J, Sheldon BC (2015) No evidence for MHC class I-based disassortative mating in a wild population of great tits. J Evol Biol 28:642-654

Setchell JM, Charpentier MJE, Abbott KM, Wickings EJ, Knapp LA (2010) Opposites attract: MHC-associated mate choice in a polygynous primate. J Evol Biol 23:136-148

Sin YW, Annavi G, Newman C, Buesching C, Burke T, Macdonald DW et al. (2015) MHC class II-assortative mate choice in European badgers (Meles meles). Mol Ecol 24:3138-3150

Skarstein F, Folstad I, Liljedal S, Grahn M (2005) MHC and fertilization success in the Arctic charr (Salvelinus alpinus). Behav Ecol Sociobiol 57:374-380

Sommer S (2005) Major histocompatibility complex and mate choice in a monogamous rodent. Behav Ecol Sociobiol 58:181-189

Song XY (2016). The genetic analysis of MHC II gene and its influence on mate choice in Rhinopithecus roxellana. $\mathrm{PhD}$ Thesis, Northwest University

Strandh M, Westerdahl H, Pontarp M, Canback B, Dubois MP, Miquel C et al. (2012) Major histocompatibility complex class II compatibility, but not class I, predicts mate choice in a bird with highly developed olfaction. Proc Biol Sci 279:4457-4463

Szulkin M, Stopher KV, Pemberton JM, Reid JM (2013) Inbreeding avoidance, tolerance, or preference in animals? Trends Ecol Evol 28:205-211

Thorbjarnarson J, Wang X (1999) The conservation status of the Chinese alligator. Oryx 33:152-159

Thorbjarnarson J, Wang X, He L (2001) Reproductive ecology of the Chinese alligator (Alligator sinensis) and implications for conservation. J Herpetol 35:553-558

Tregenza T, Wedell N (2000) Genetic compatibility, mate choice and patterns of parentage: invited review. Mol Ecol 9:1013-1027

Wang XY, Wang D, Wu XB, Wang RP, Wang CL (2006) Congregative effect of Chinese alligator' $\mathrm{s}$ bellowing chorus in mating season and its function in reproduction. Acta Zool Sin $52: 663-668$

Wang ZH, Yao H, Ding YZ, John T, Wang XM (2011) Testing reintroduction as a conservation strategy for the critically endangered Chinese alligator: movements and home range of released captive individuals. Chin Sci Bull 56:2586-2593

Wang J (2002) An estimator for pairwise relatedness using molecular markers. Genetics 160:1203-1215

Wang J (2011) COANCESTRY: a program for simulating, estimating and analysing relatedness and inbreeding coefficients. Mol Ecol Resour 11:141-145

Westerdahl H (2004) No evidence of an MHC-female mating preference in great reed warblers. Mol Ecol 13:2465-2470

Wan QH, Pan SK, Hu L, Zhu Y, Xu PW, Xia JQ et al. (2013) Genome analysis and signature discovery for diving and sensory properties of the endangered Chinese alligator. Cell Res 23:1091-1105

Waser PM, Austad SN, Keane B (1986) When should animals tolerate inbreeding. Am Nat 128:529-537

Yamazaki K, Boyse EA, Mike V, Thaler HT, Mathieson BJ, Abbott J et al. (1976) Contral of mating preferences in mice by genes in major histocompatibility complex. J Exp Med 144:1324-1335

Yang HQ, Zhao L, Han QH, Fang SG (2017) Nest site preference and fidelity of Chinese alligator (Alligator sinensis). Asian Herpetol Res 8:244-252

Zeh JA, Zeh DW (1996) The evolution of polyandry I: Intragenomic conflict and genetic incompatibility. Proc R Soc 263:1711-1717

Zhang F, Messenger K, Wang Y (2015) Relationship between nest defence behaviours and reproductive benefits in Chinese alligators. Amphib Reptil 36:141-147

Zhao L, Yang HQ, Fang LM, Pan GL, Zou WQ, Ren DB et al. (2013) The sex ratio of wild Chinese alligators Alligator sinensis. Curr Zool 59:725-731

Zhao JH, Zhou YK, Wang SS, Tu GJ, Tang XN, Wu XB (2015) Preliminary report on the intestinal parasites and their diversity in captive Chinese alligators. Nutr Hosp 31:813-819

Zhu Y (2014). MHC-based female choice in giant panda. Postdoctoral Report, Zhe Jiang University 